\title{
A review on the application of the theory of critical distance towards concrete
}

\author{
Mohamad Shazwan Ahmad Shah ${ }^{1, *}$, Norhazilan Md. Noor ${ }^{1}$, Ahmad Beng Hong Kueh ${ }^{1}$ and \\ Mohd. Nasir Tamin ${ }^{2}$ \\ ${ }^{1}$ Faculty of Civil Engineering, Universiti Teknologi Malaysia, 81310 Skudai, Johor Bahru, Malaysia \\ ${ }^{2}$ Faculty of Mechanical Engineering, Universiti Teknologi Malaysia, 81310 Skudai, Johor Bahru, \\ Malaysia
}

\begin{abstract}
Theory of Critical Distance (TCD) is one of Fracture Mechanics numerical model that has gone through tremendous laboratory works and validation. Hence, it has been proven to be precise in broad perspectives in the field. Recently, TCD research related to fracture, especially fatigue on concrete are growing but the depth of study is still shallow and deficient compared to metal and steel. Thus, this made the fracture assessment in concrete obscures and governs by uncertainties. Previous efforts have managed to optimize TCD but the results only valid if the water-cement ratio of a concrete specimen in its optimum level. When the water-cement ratio is adjusted to a higher or lower from its optimum level, the output errors showed inconsistency as reported by Luca Susmel (2016). Therefore, this research aims to optimize the Theory of Critical Distance (TCD) by incorporating water-cement ratio and the interaction of microstructure matrix. The optimization involves few stages and finite element. If Theory of Critical Distance (TCD) can be improved by considering concrete's additional element in its mathematical expression, it will definitely contribute to betterment in assessing concrete infrastructure around the globe.
\end{abstract}

\section{Introduction}

"The Versailles Train Crash of 1842" is always said that this tragedy is the departure point in understanding the mechanism of cyclic fatigue. At that time, people did not realise that build-up of small stress cycles could lead to a crack and sudden failure [1]. Following the tragedy, the study in fatigue is progressing until current. But up to current progress, fatigue is known dominantly on metal and steel [2]. There are steady guidelines and formulations established for fatigue and fracture in steel and metal components. The sound studies in fatigue especially on metal and steel make the engineers today have high confidence to use and incurred fatigue element in their design - it is easy to understand and implement.

\footnotetext{
* Corresponding author: mohamadshazwan.ahmadshah@gmail.com
} 
In reality, not only steel or metals but concrete structures also continually experienced repeated loading or also called fatigue loading. It is known that the study on concrete has been broadly branched until current and it continues [3][4]. However, there are some fragment of concrete study is noticed to be deficit, which is fatigue and fracture mechanics.

Although at the very beginning of the last century to the latest study in fatigue and fracture taking place tremendously, there are still no recognized agreements in methods to perform the fatigue assessment of concrete - and no organized works done to cultivate specific method or standard to suit the condition of detrimental effect of notches on plain concrete subjected to cyclic loading [5]. Fatigue is being very subjective on its application on concrete. While engineers are confident on concrete study and its applications and contributions to the world's constructions, some of them overlooked the design and might neglect the consequences from the repeated cyclic loading.

In this challenging situation, the study endeavours of using the so-called Theory of Critical Distances (TCD) to perform the repeated and static cycle fatigue assessment of notched plain concrete. Recently, researches relating fatigue on concrete are growing but the depth of study is still shallow and lacking compared to metal and steel [6]. The trivialities in fatigue in concrete will be projected to improvise the Theory of Critical Distance (TCD) either from its conceptual or numerical perspectives with attuning to the variation of water-cement ratio.

The Theory of Critical Distance (TCD) has been proven to be accurate in various perspectives of Fracture Mechanics [7]. Professor Luca Susmel (2006) and Professor David Taylor (2007) claimed that TCD is suitable for practical interest like industrial engineers and it is well-proven. As to implant confidence in the mechanics, every study relating TCD will be controlled over minimal allowance of error.

However, based on one of the recent findings in Professor Luca Susmel in year 2016 where he applied the formalisation on two batches of concrete specimen - both batches of concrete are made of different water-cement ratio, it was found out the error on the same notch modes but different water-cement ratio, are severely high. Therefore, the Theory of Critical Distance (TCD) must be investigated further - to identify its consistency and application on different water-cement ratio in concrete composition.

Through this study, it will definitely increase the understanding in the Theory of Critical Distance (TCD) and enhance its application in future. This will embark the journey of static and fatigue study in concrete to become more emphasize. The study is suggested to be more careful and thorough when making the concrete specimen. It is because fracture testing especially concrete might be bare to many mistakes and uncertainties.

The study aims to propose a characterise crack in concrete governs by water-cement. The characterisation is based on the Theory of Critical Distance (TCD) framework. The technique based on the use of local stresses suitable for estimating fatigue damage in notched concrete components subjected to fatigue and static loading.

Generally, the study of fatigue in concrete is important to ensure the design of a structure includes defect-tolerant design philosophy. Secondly, it is essential for engineers to understand the phases in fatigue cracks. Through the study, either engineers or researchers are able to use Theory of Critical Distances (TCD) and apply it in concrete study with confidence and zero-reluctance. Therewithal, the reason and parameter affecting 
TCD's precision when bump into cases of static and fatigue with different water-cement ratio in concrete will be revealed - and TCD will be more sensitive to its application on concrete. Besides, unexpected and sudden failure can be avoided by understanding purely the material's fatigue endurance limit. Despite addressing stress in every design calculation, material's toughness and endurance limit should not be put aside. Engineers have to realise that static and fracture mechanics are related and should not distinguish them apart as what happened in previous decades - structures will be better in quality in any way.

\section{Literature Review}

The components in concrete structures often never are as perfect as the engineered component. Surface irregularities, metallurgical of metal structures, and sizes are some of the features that engineers will need to inspect before installation. The worry arises when these imperfections create stress concentrations through notches and cracks. The stress concentrations are sensitive - if a material having a notch or crack, applied with any external force even if the force is small, the force at the notch or crack tip will be greater amplified [8] - and this is the study related to fatigue, which is often left behind compared to steel and metal when comes to fatigue analysis.

In structural engineering realm, engineers always wanted the most practical and high accuracy formulation for them to incurred into their design calculations. Elasto-plastic fracture mechanics (EPFM) is one of the well-known extension of Fracture Mechanics which consider further plasticity energy at the notch tips [9]. Nevertheless, the challenging part of this technique is it requires high level of experience and its numerical modelling is massive [10].

In the study, concrete is the material of matter - concrete is a classified as a brittle material although it does allow severe plasticity [11]. To be more detail from modern fracture mechanics perspective, concrete is considered as a quasi-brittle material as it does have some dissimilarity to ideal brittle material [12]. Hereby, the motivation of the study will be shifted to concentrate on linear-elastic fracture mechanics by obeying its law.

Research about fatigue and fracture on its application towards concrete progressively recognized in the recent modern practice because the design safety factors are reducing from the past [13]. Based on engineering understanding, the lower the safety factor means lower the ultimate stress, consequently smaller size of concrete structural component and less concrete used. The decrement in size of concrete structural components leads to more problems involving fatigue and fracture - it has higher chance for local stresses to occur, making the structures more prone to fatigue [14].

Concerning fatigue, sometimes it might increase slightly the usage of concrete unfortunately it is not a good news for the healthy environment. Currently, the world is rushing towards sustainability as to save the planet. Thus, researchers on concrete especially who involves closely in making the procedures of the Eurocode (EC), or American Concrete Institute (ACI) are trying their best to reduce the concrete consumption in their calculations and practice without jeopardizing its strength [15]. Henceforward, fatigue study in concrete structure no longer be neglected [16]. 


\subsection{Theory of Critical Distance}

The idea in analysing fatigue and fracture being addressed (by Taylor (2010) interpreted from Neuber (1936) and Peterson (1959) work) is measuring the maximum stress at the notch root - the high stress will then steadily decrease over distances away from the notch tip - the concept is called the Theory of Critical Distances [17].

The Theory of Critical Distances (TCD) is a group of formalization used to predict the effect/fatigue strength at notches or other stress concentration features region [7]. TCD has been used for years and recently it has been brought up by linking it with LEFM - TCD is based on critical distance from notch root and represents the extension of linear elastic fracture mechanics (LEFM) principles [18].

The Theory of Critical Distances (TCD) successfully analyses and explain notch sensitivity study in a vast scope. TCD is effectively workable in different notch modes; from the sharp notch cases like cracks [19][20] to the blunt notch like surface irregularities [21][22][23][24]. TCD can corresponds very fine under entire range of cycles; low-cycles fatigue loading [25], medium-cycle fatigue loading [7][26][27], and high-cycle fatigue loading [28][29][5][18]). In term of morphological viewpoint, TCD is a formalization which is suitable for brittle and quasi-brittle ([30][31][32]).

There are also other approaches catering fracture in concrete [33][34][35][36]). But in the latest trending of the research in this scope is getting rid by two models; Size Effect by Zdeněk Pavel Bažant (Bažant) and Boundary Effect by Xiaozhi Hu/ Kai Duan (Hu/Duan).

Bažant's emphasized when the failure did not happened at crack initiation then the concrete specimen are subjected to size dependency [37]. Based on Bažant, if this case occurs, the model should properly handle the macro-crack growth and able to explain from energy outlook [38]. Conversely, Hu claimed that Bažant's Size Effect model was not that well-organized as he did not particularly stressed on the effect of grain size in studying fracture behaviour in concrete [39]. Meanwhile Hu's Boundary Effect was being very specific and detail capturing fracture in concrete to the extent of incurring aggregate size and fictitious crack mode in their analysis [40].

It is undeniable Hu's Boundary Effect Model is astonishing but the model did not reach the study of fatigue or cyclic loading prior to time onto concrete. Additionally, Hu-Duan's Boundary Effect was criticized by few professionals such as Christian G. Hoover and Bažant himself declaring the Boundary Effect was only precise in a tiny scope of the field and unreliable enough if to be applied throughout the ground [41]. This give a lead in Theory of Critical Distances (TCD) in catering cases as mentioned. Enhancing TCD in its formulation considering more practical factor will certainly makes good to the field.

Throughout the study, Theory of Critical Distances (TCD) will be the fundamental and based on few examples of research done as stated above, one should realise TCD has good evidences and great benefits in studying fracture mechanics field compared to several conventional method which these characterisations are not as vibrant as TCD. The Theory of Critical Distances is one of the best well-known formalizations and it satisfies cases in this study harmoniously with the condition of high-cycle fatigue loading on brittle and quasi-brittle material like concrete [18]. However, the study arises the concern when the error in TCD applications variate due to one of the change of one of the concrete's basic mix design -water-cement ratio. Thus, the aim of the study will help the research to cater 
issues on sensitivity of the Theory of Critical Distances (TCD) on its application to the concrete under fatigue condition with different water-cement ratio.

\subsection{Research Progress in Fatigue and Fracture in Concrete}

Analysis of structures under fatigue loading with fluctuating stresses and strains amplitude with respect to time on concrete structure has been discovered since 1900 - however, it was studied by distinctive phenomena [42].

Personally, the study would give a special acknowledgement in developing fracture mechanics field from various aspects - Charles Edward Inglis (1875-1952), Alan Arnold Griffith (1893 - 1963), George Rankin Irwin (1907 - 1998), and Harold Malcolm Westergaard (1888 - 1950). Then, followed by the researchers who directly get involves in the research of fracture in concrete and especially to whom utilizing the Theory of Critical Distance (TCD).

Sir Charles Edward Inglis is one of the most remarkable researchers in fracture mechanics field and deliberated as he was considered the earliest to break through the field. In year 1913, he published his infamous discussion at that time titled "Stress in a plate due to the presence of cracks and sharp corners". Later in year 1921 by an English aeronautical engineer, Alan Arnold Griffith of the Royal Aircraft Establishment in the United Kingdom with the lead of the mathematical work of Professor Sir Charles Edward Inglis. He became fascinated in effect of scratches and surface finish on metals subjected to fatigue loading [12]. Then, Dr. George Rankin Irwin, an American expert in fracture mechanics and materials [43] extended Griffith's approach by refining the definition of energy release within the plastic zone [44][12]). Nextly, Professor Harold Malcolm Westergaard went deep into studying bearing effect and cracks, and eventually explored the theory of elasticity and plasticity [45]. 


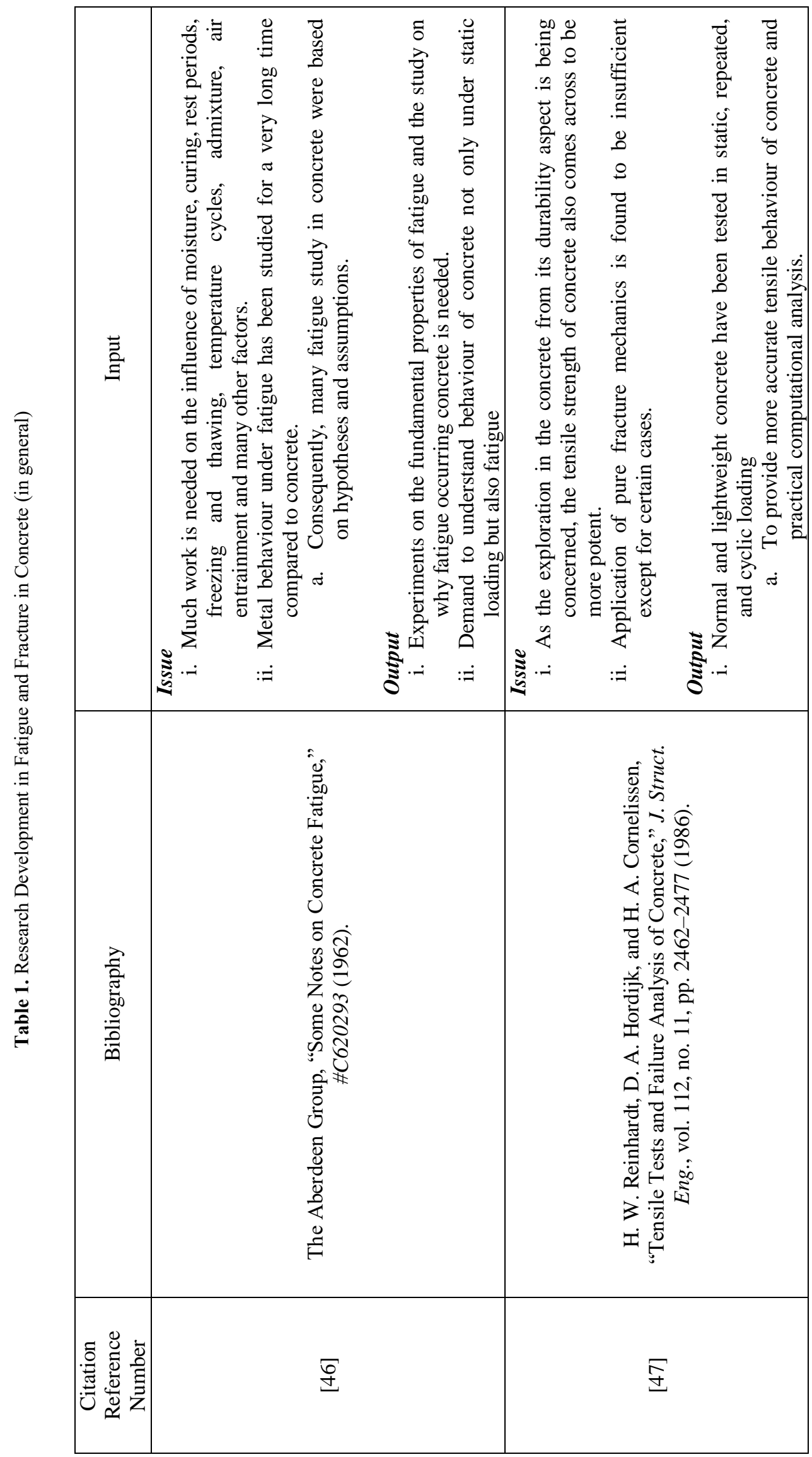




\begin{tabular}{|c|c|c|c|}
\hline 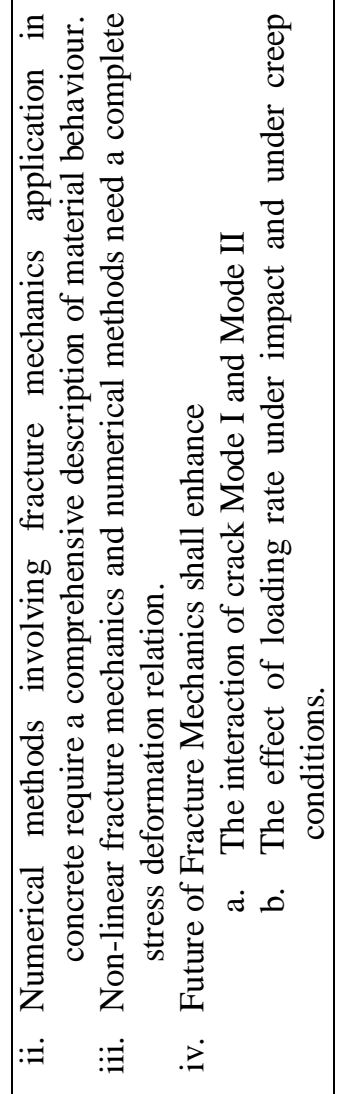 & 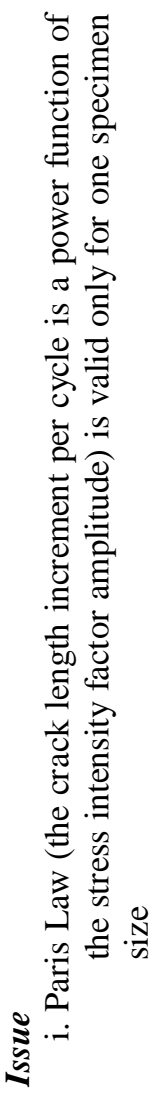 & 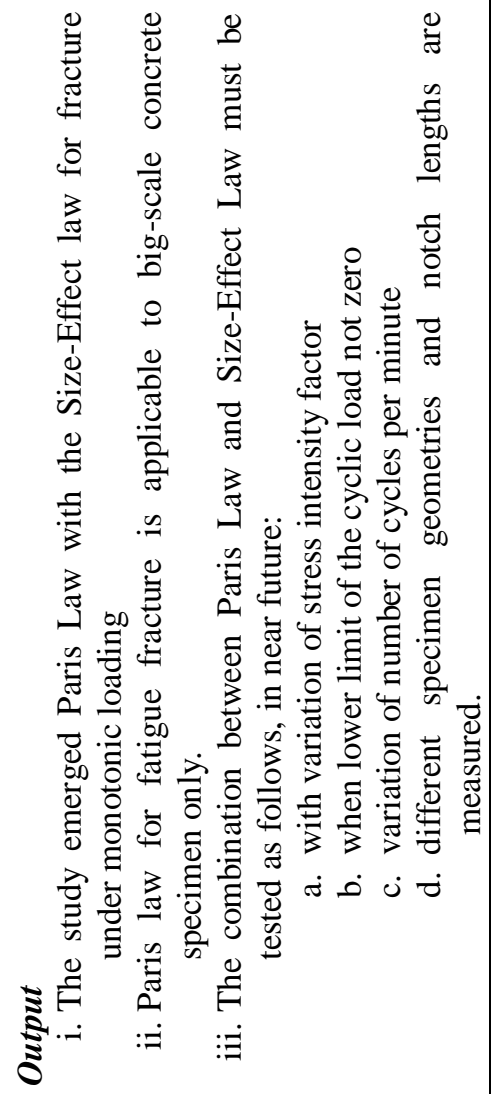 & 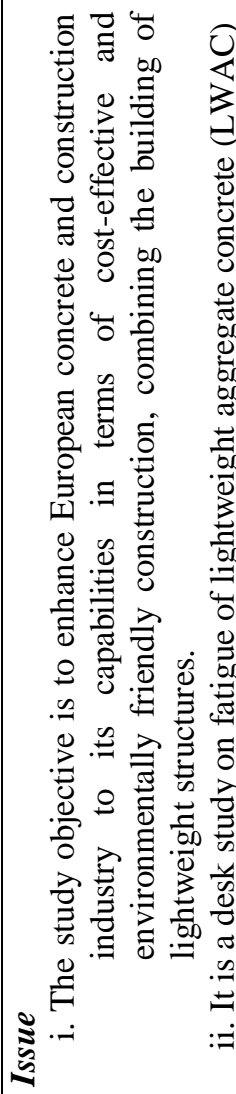 \\
\hline & & 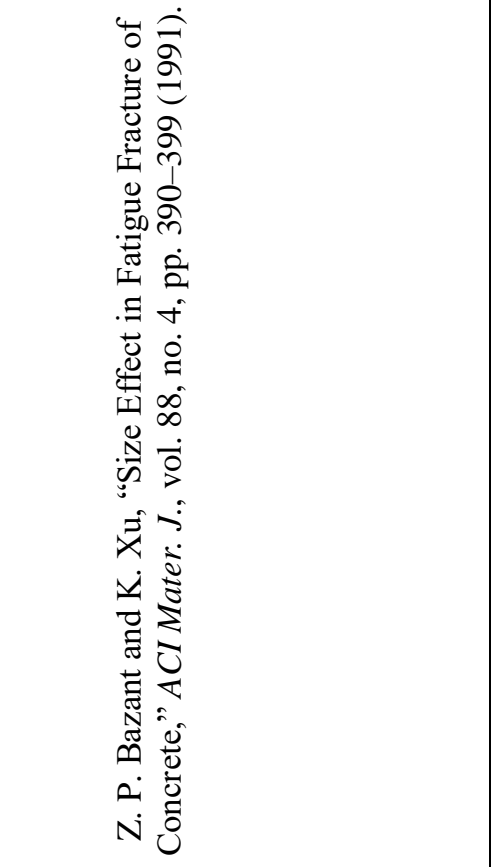 & 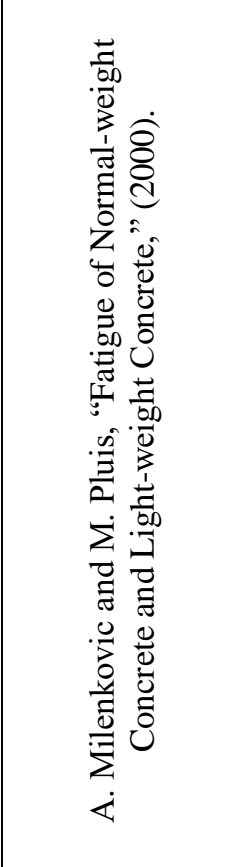 \\
\hline & & 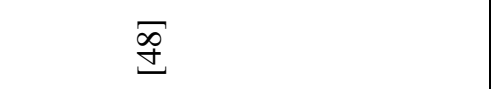 & 守 \\
\hline
\end{tabular}




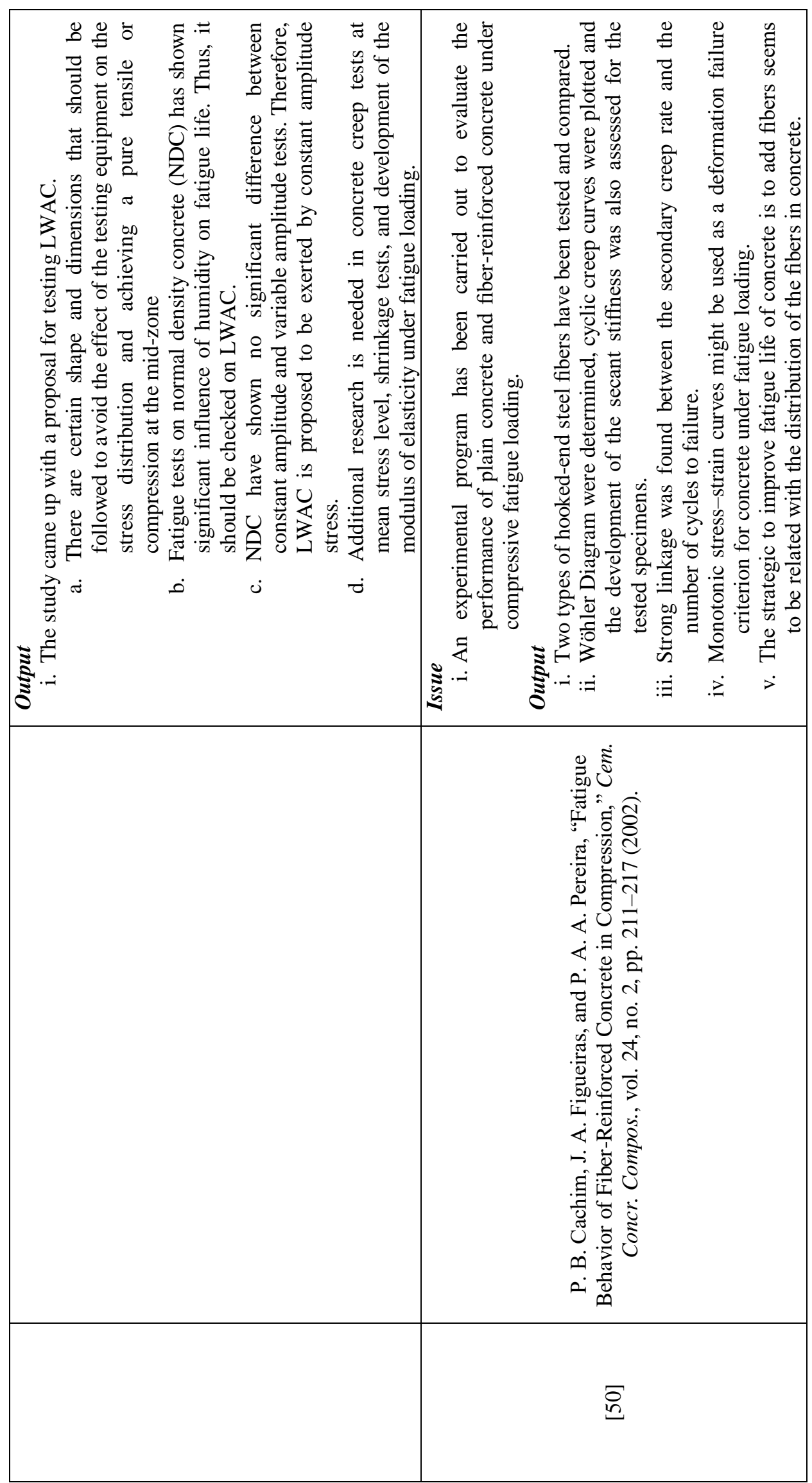




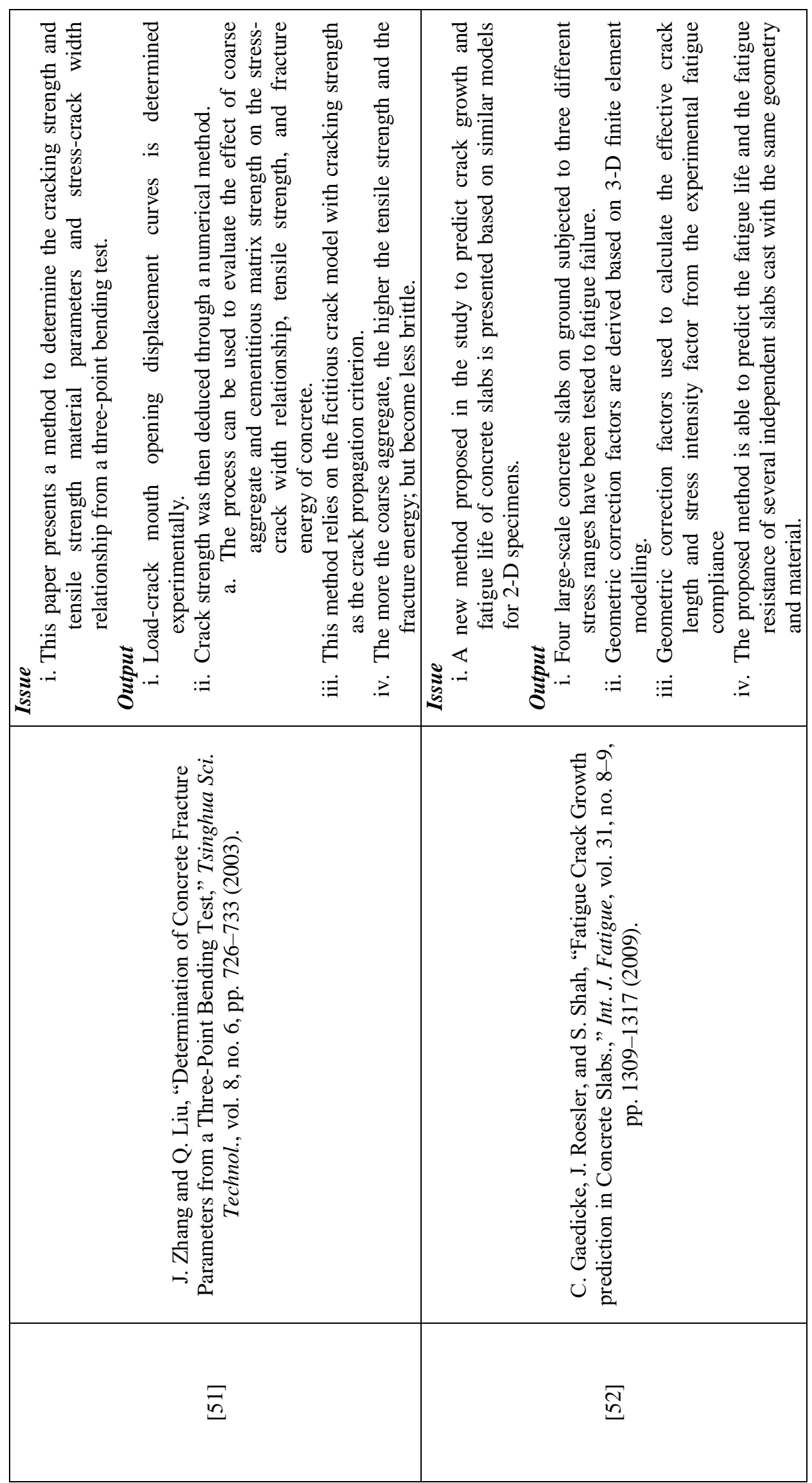




\begin{tabular}{|c|c|c|c|c|}
\hline 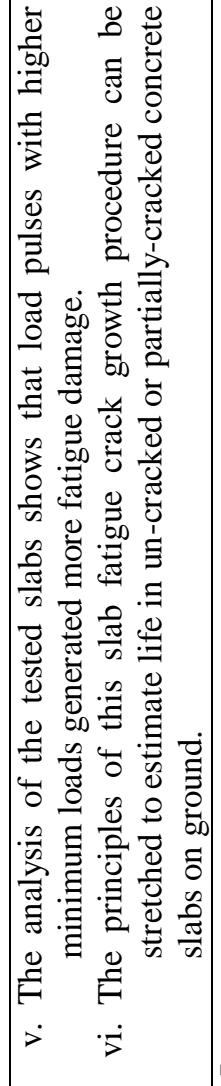 & 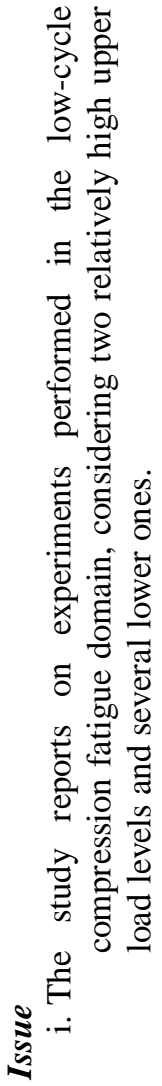 & 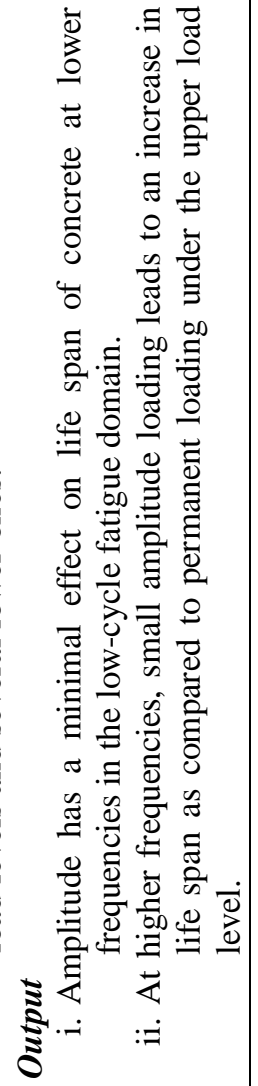 & 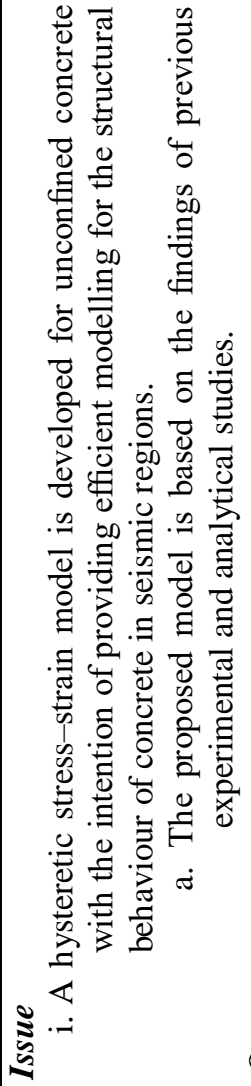 & 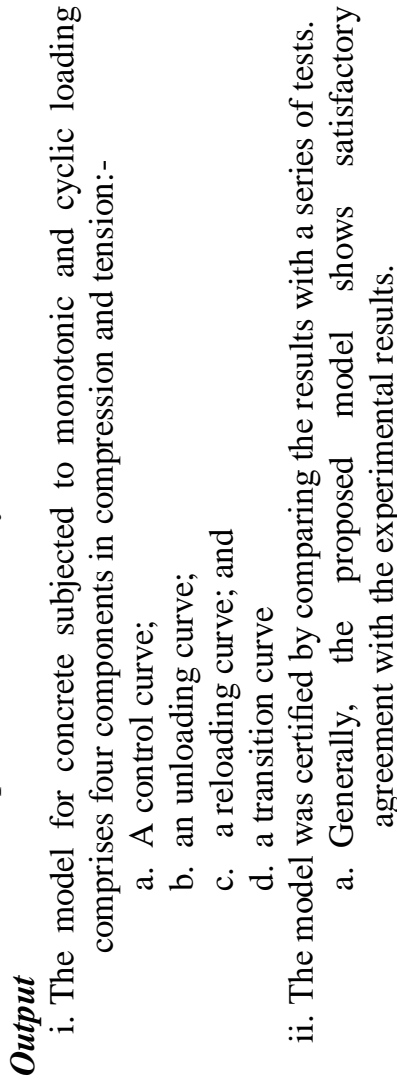 \\
\hline & & 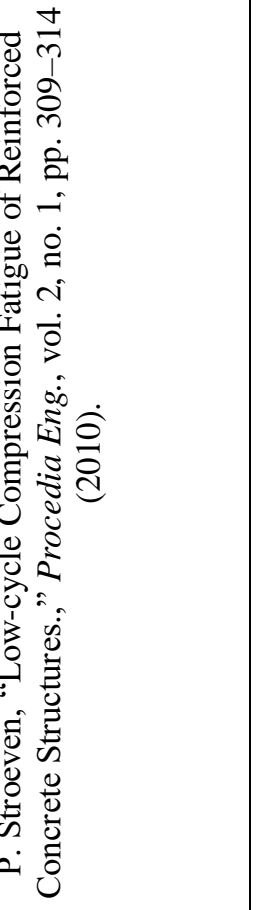 & & 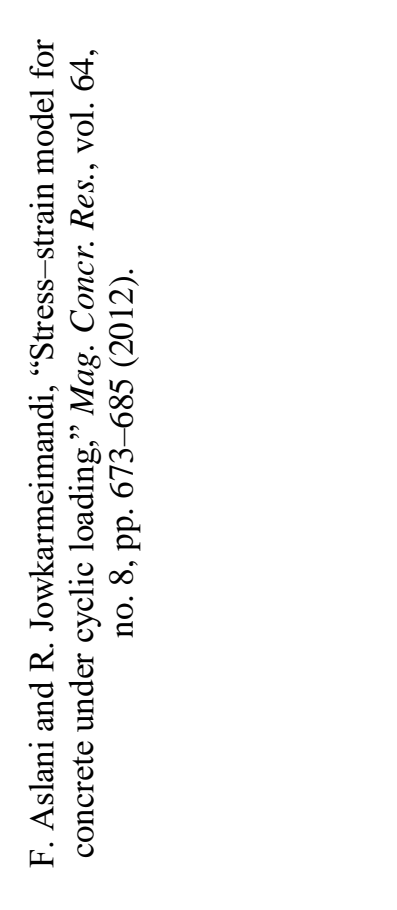 \\
\hline & & $\sqrt[\tilde{n}]{n}$ & & 苞 \\
\hline
\end{tabular}




\begin{tabular}{|c|c|c|c|}
\hline & 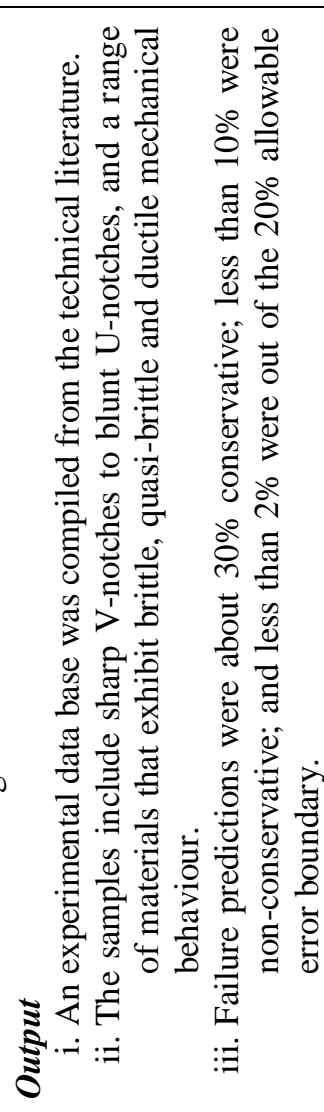 & 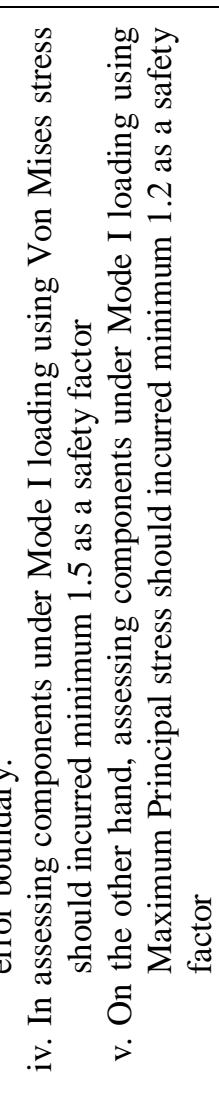 & 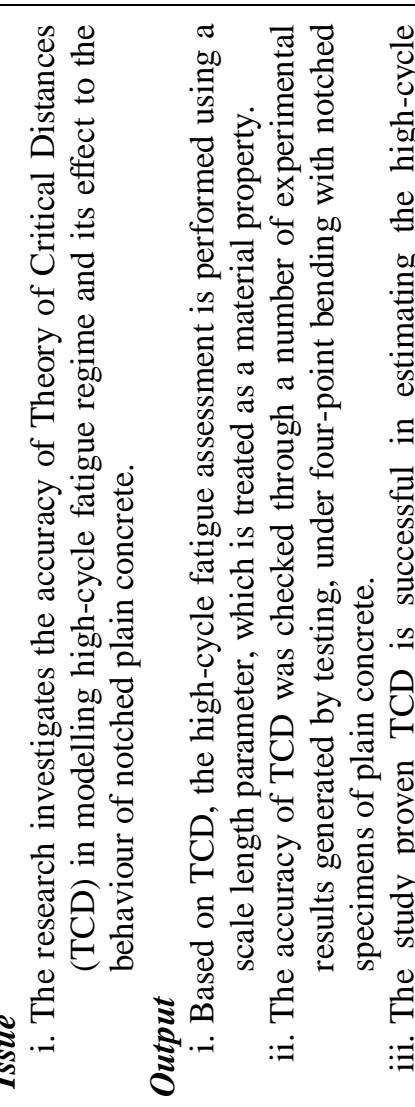 \\
\hline - & \multicolumn{2}{|l|}{ 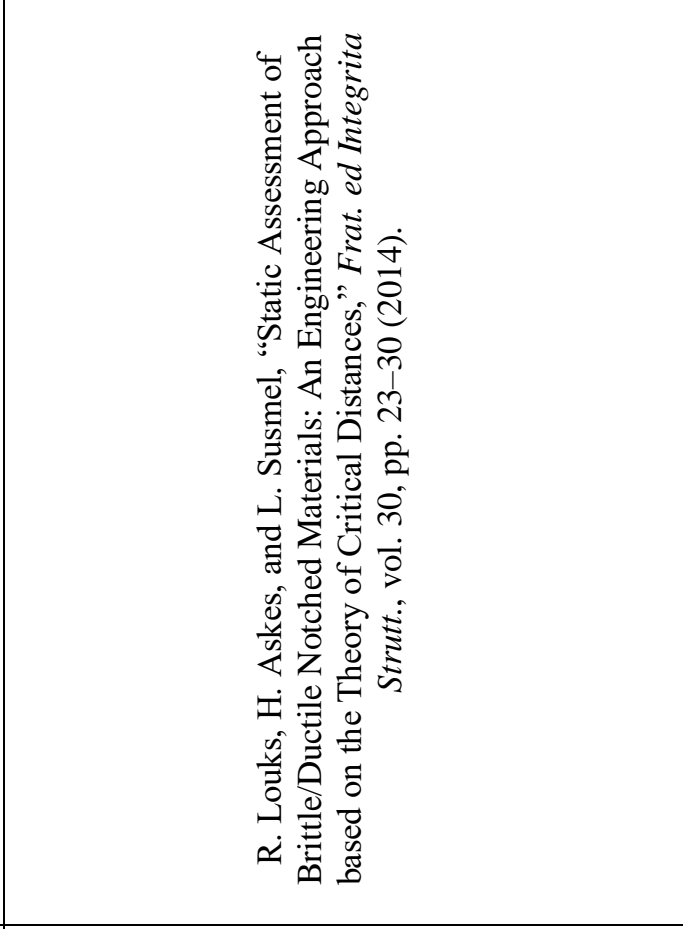 } & 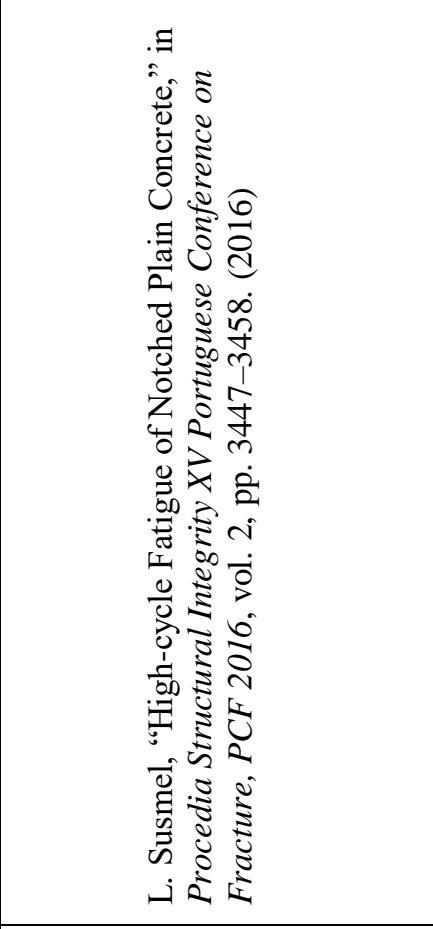 \\
\hline & \multicolumn{2}{|l|}{$\overline{\vec{m}}$} & in \\
\hline
\end{tabular}




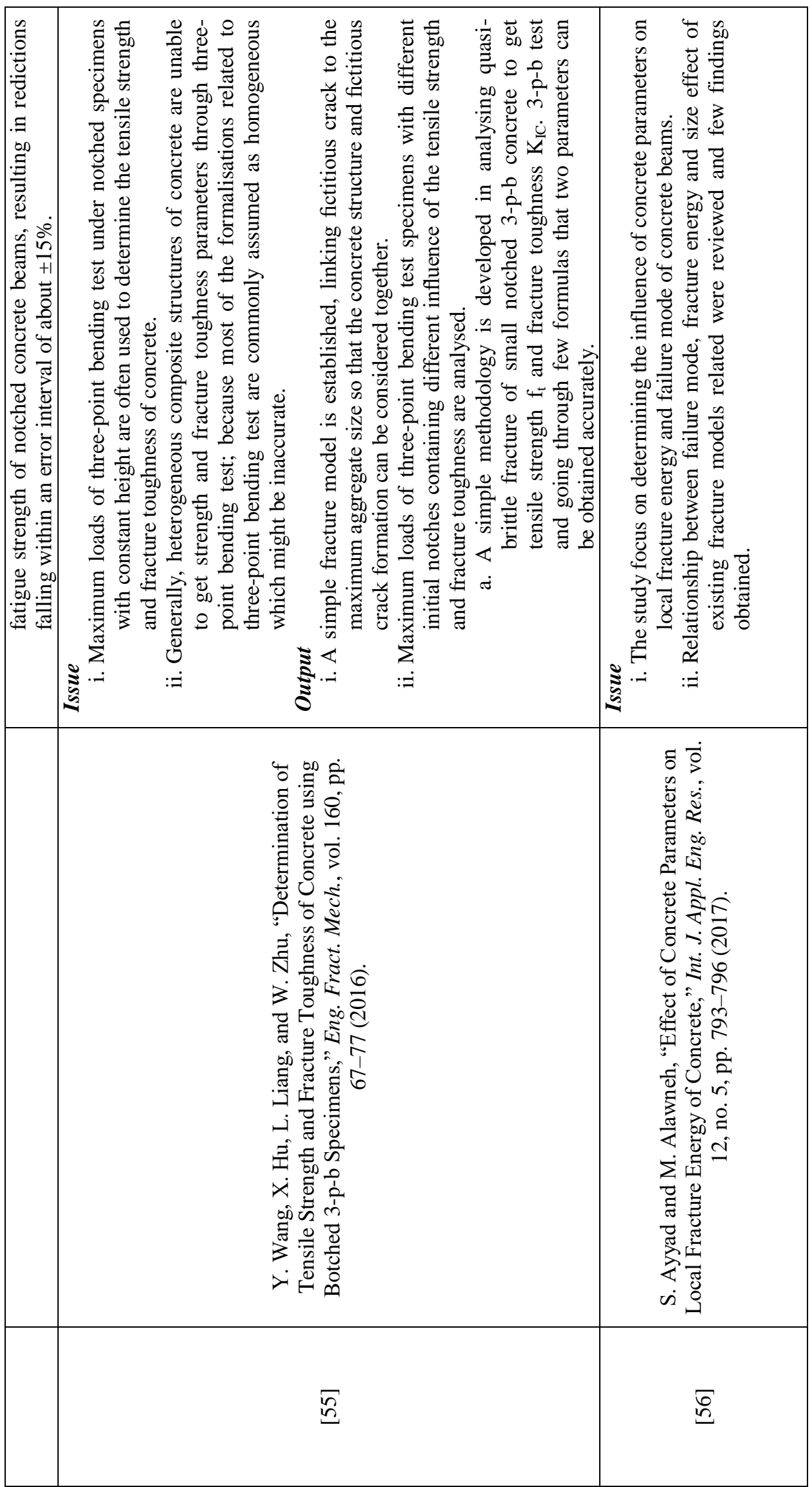




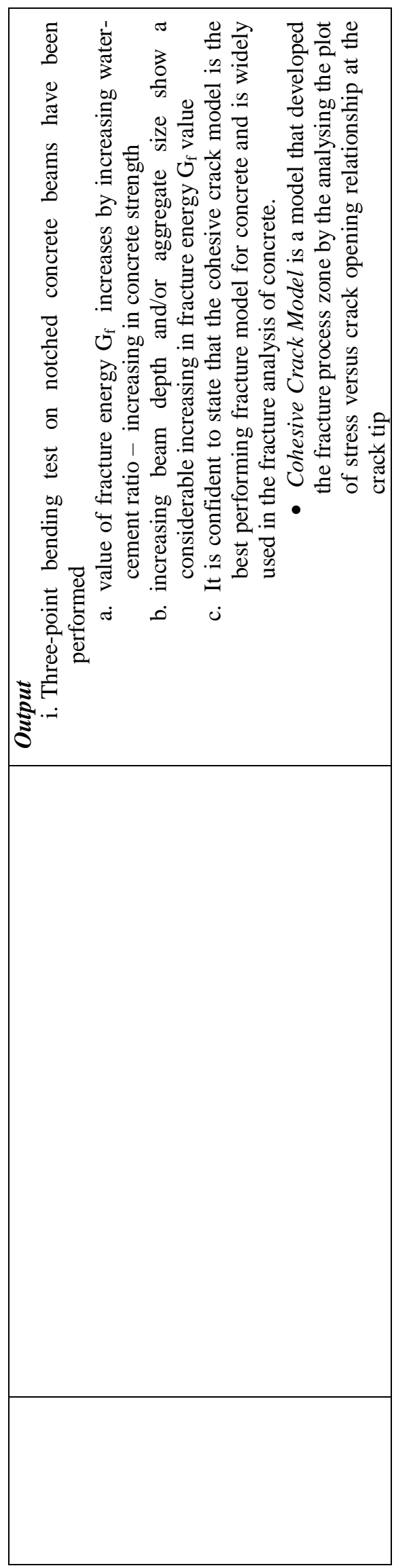




\section{Summary}

The concern on fracture mechanics has begun in the early of the 20th century where Inglis (1913) studied on crack in plate. Then, the concept and formulations were sharpened as time goes by; fracture study has become even more important when World War II. But, almost every fracture study only involves steel and metal. In the middle of 20th century, researcher started to realise the importance of considering fatigue and fracture study in concrete. Starting that point, more researchers begin to determine and analyse fracture properties of concrete. The tests on concrete involve every range of scope; lightweight, normal-weight, and heavy-weight concrete. In fact, some of the experiments were testing concrete under fatigue loading. As the concrete's fracture parameters were mostly welldefined at that time, the derivation grew even deeper by analysing the fracture process zone, fatigue crack growth, critical number of cycles to failure, so on and so forth. As fracture mechanics in concrete getting matured, some of the researchers took the opportunity to simplify the testing involving concrete's fracture because fracture test on concrete was not easy. The simplifications were meant to benefit the industry. The simplifications were not only meant for experimental scope but it developed by simplifying the concept and formulations too.

Fracture mechanics has many more brances in the field such as Wöhler Curve method, Elastic-Plastic Fracture Mechanics (EPFM), Linear-Elastic Fracture Mechanics (LEFM), the Theory of Critical Distances (TCD), Critical Plane approach, Manson-Coffin Curve method (MCCM), Gradient Elasticity, Boundary Effect Method (BEM), Size Effect Method (SEM) etc. However, the Theory of Critical Distances (TCD) is lighter and more practical for industry [57][58].

The Theory of Critical Distances is one of the best well-known formalizations and it satisfies cases in this study harmoniously with the condition of high-cycle fatigue loading on brittle and quasi-brittle material like concrete [18]. However, the study arises the concern when the error in TCD applications variate with respect to one of the concrete fatigue strength's aspects - which is water-cement ratio. Of all researches as listed above, there were a little gap which might enhance fracture mechanics application in a better way. Thus, the aim of the study will help the research to cater issues on sensitivity of the Theory of Critical Distances (TCD) on its application to the concrete with different water-cement ratio.

\section{References}

1. G. Sendeckyj, "Early Railroad Accidents and the Origins of Research on Fatigue of Metals.," Mater. Manuf. Dir. Air Force Res. Lab. Wright-Patterson Air Force Base, 2006.

2. E. Santecchia, A. M. S. Hamouda, F. Musharavati, E. Zalnezhad, M. Cabibbo, M. El Mehtedi, and S. Spigarelli, "A Review on Fatigue Life Prediction Methods for Metals.," Adv. Mater. Sci. Eng., 2016.

3. L. Bisby, H. Mostafaei, and P. Pimienta, "State-of-the-art on Fire Resistance of Concrete Structure-Fire Model Validation.," NIST-Special Publ. Int. R\&D Road Map Fire Resist. Struct., 2014.

4. $\quad$ P. A. Buchan and J. F. Chen, "Blast Protection of buildings using fibre-reinforced polymer (FRP) composites.," Blast Prot. Build. using Fibre-Reinforced Polym. Compos., pp. 269-297, 2010. 
5. L. Susmel, "High-cycle Fatigue of Notched Plain Concrete," in Procedia Structural Integrity XV Portuguese Conference on Fracture, PCF 2016, 2016, vol. 2, pp. $3447-$ 3458.

6. D. M. Frangopol, M. Akiyama, and H. Furuta, Life-cycle of structural systems: Design, Assessment, Maintenance and Management. CRC Press, 2014.

7. L. Susmel and D. Taylor, "A Novel Formulation of the Theory of Critical Distances to Estimate Lifetime of Notched Components in the Medium-Cycle Fatigue Regime," Fatigue Fract. Eng. Mater. Struct., vol. 30, no. 7, pp. 567-581, 2007.

8. W. D. Pilkey, Peterson's Stress Concentration Factors. Wiley, New York, 1997.

9. A. Fatemi, "Fundamentals of LEFM and Applications to Fatigue Crack Growth," in University of Toledo, 2010, p. 133.

10. L. Susmel, "The Theory of Critical Distances: A Review of Its Applications in Fatigue," Eng. Fract. Mech., vol. 75, no. 7, pp. 1706-1724, 2008.

11. L. Ceriolo and A. Di Tommaso, "Fracture Mechanics of Brittle Materials: A Historical Point Of View.," in 2nd Symposium in Civil Engineering, Budapest, 1998.

12. T. L. Anderson, Fracture Mechanics: Fundamentals and Applications, vol. 58, no. 1. 2017.

13. J. Sutherland, R. J. . Sutherland, H. Dawn, and M. Chrimes, Historic Concrete: Background to Appraisal. Thomas Telford, 2001.

14. K. Stamoulis and A. E. Giannakopoulos, "Size Effects on Strength, Toughness and Fatigue Crack Growth of Gradient Elastic Solids," Int. J. Solids Struct., vol. 45, no. 18-19, pp. 4921-4935, 2008.

15. O. Jadallah, C. Bagni, H. Askes, and L. Susmel, "Microstructural Length Scale Parameters to model the High - Cycle Fatigue Behaviour of Notched Plain Concrete," Int. J. Fatigue, vol. 82, pp. 708-720, 2016.

16. L. Susmel, "Nominal Stresses and Modified Wöhler Curve Method to perform the Fatigue Assessment of Uniaxially Loaded inclined Welds," in Proceedings of the Institution of Mechanical Engineers, Part C: Journal of Mechanical Engineering Science, 2014, vol. 228, no. 16, pp. 2871-2880.

17. R. Daud, A. Ahmad Kamal, S. Abdullah, and A. E. Ismail, "Fatigue Failure Analysis using The Theory of Critical Distance," Key Eng. Mater., vol. 462-463, pp. 663-667, 2011.

18. D. Taylor, "Analysis of Fatigue Failures in Components using the Theory of Critical Distances," Eng. Fail. Anal., vol. 12, no. 6, pp. 906-914, 2005.

19. L. Susmel and D. Taylor, "Two Methods for Predicting the Multiaxial Fatigue Limits to Sharp Notches," Fatigue Fract. Eng. Mater. Struct., vol. 26, no. 9, pp. 821-833, 2003.

20. H. Askes, P. Livieri, L. Susmel, D. Taylor, and R. Tovo, "Intrinsic Material Length, Theory of Critical Distances and Gradient Mechanics: Analogies and Differences in Processing Linear-Elastic Crack Tip Stress Fields," Fatigue Fract. Eng. Mater. Struct., vol. 36, no. 1, pp. 39-55, 2013.

21. D. Taylor, "Predicting the Fracture Strength of Ceramic Materials using the Theory of Critical Distances," Eng. Fract. Mech., vol. 71, no. 16-17, pp. 2407-2416, 2004.

22. D. Taylor, M. Merlo, R. Pegley, and M. . Cavatorta, "The Effect of Stress Concentrations on the Fracture Strength of Polymethylmethacrylate," Mater. Sci. Eng. A, vol. 382, no. 1-2, pp. 288-294, 2004. 
23. D. Taylor, P. Cornetti, and N. Pugno, "The Fracture Mechanics of Finite Crack Extension," Eng. Fract. Mech., vol. 72, no. 7, pp. 1021-1038, 2005.

24. D. Taylor, "The Theory of Critical Distances Applied to the Prediction of Brittle Fracture in Metallic Materials," Struct. Integr. Durab., vol. 1, no. 2, pp. 1-9, 2006.

25. T. Hattori, A. W. M.A.B., T. Ishida, and M. Yamashita, "Fretting Fatigue Life Estimations based on the Critical Distance Stress Theory.," Procedia Eng., vol. 10, pp. 3134-3139, 2011.

26. D. Taylor, S. Kasiri, and E. Brazel, "The Theory of Critical Distances applied to Problems in Fracture and Fatigue of Bone.," Atti del XX Convegno Naz. del Grup. Ital. Frat., p. 11, 2009.

27. R. Louks and L. Susmel, "The Linear-Elastic Theory of Critical Distances to estimate High-Cycle Fatigue Strength of Notched Metallic Materials at Elevated Temperatures," Fatigue Fract. Eng. Mater. Struct., vol. 38, no. 6, pp. 629-640, 2015.

28. L. Susmel, "A Unifying Approach to estimate the High-Cycle Fatigue Strength of Notched Components subjected to both Uniaxial and Multiaxial Cyclic Loadings," Fatigue Fract. Eng. Mater. Struct., vol. 27, no. 5, pp. 391-411, 2004.

29. L. Susmel and D. Taylor, "A Simplified Approach to apply the Theory of Critical Distances to Notched Components under Torsional Fatigue Loading," Int. J. Fatigue, vol. 28, no. 4, pp. 417-430, 2006.

30. F. Pessot, L. Susmel, and D. Taylor, "The Theory of Critical Distances to predict Static Strength of Notched Brittle Components subjected to Mixed-mode Loading," Eng. Fract. Mech., vol. 75, no. 3-4, pp. 534-550, 2008.

31. R. Louks, H. Askes, and L. Susmel, "Static Assessment of Brittle/Ductile Notched Materials: An Engineering Approach based on the Theory of Critical Distances," Frat. ed Integrita Strutt., vol. 30, pp. 23-30, 2014.

32. I. Pelekis and L. Susmel, "The Theory of Critical Distances to estimate static and dynamic strength of notched plain concrete," Procedia Struct. Integr., vol. 2, pp. 2006-2013, 2016.

33. A. Hillerborg, M. Modéer, and P. E. Petersson, "Analysis of Crack Formation and Crack Growth in Concrete by means of Fracture Mechanics and Finite Elements," Cem. Concr. Res., vol. 6, no. 6, pp. 773-781, 1976.

34. Y. S. Jenq and S. . Shah, "Features of Mechanics of Quasi-Brittle Crack Propagation in Concrete," Curr. Trends Concr. Fract. Res., no. Springer, Dordrecht, pp. 103-120, 1991.

35. Z. P. Bazant and B. H. Oh, "Deformation of Progressively Cracking Reinforced Concrete Beams," J. Am. Concr. Inst., vol. 3, no. 81, pp. 268-278, 1984.

36. B. . Karihaloo, Fracture Mechanics \& Structural Concrete, Concrete D. 1995.

37. X. Gao, G. Koval, and C. Chazallon, "A Size and Boundary Effects Model for QuasiBrittle Fracture," Materials (Basel), vol. 9, no. 12, p. 1030, 2016.

38. G. A. Rao and B. R. Prasad, "Influence of the Roughness of Aggregate Surface on the Interface Bond Strength,” Cem. Concr. Res., vol. 32, no. 2, pp. 253-257, 2002.

39. X. Hu, J. Guan, Y. Wang, A. Keating, and S. Yang, "Comparison of boundary and size effect models based on new developments,” Eng. Fract. Mech., vol. 175, pp. 146-167, 2017.

40. J. Guan, X. Hu, and Q. Li, "In-depth Analysis of Notched 3-p-b Concrete Fracture," Eng. Fract. Mech., vol. 165, pp. 57-71, 2016.

41. Q. Yu, J.-L. Le, C. G. Hoover, and Z. P. Bažant, "Problems with Hu-Duan Boundary 
Effect Model and Its Comparison to Size-Shape Effect Law for Quasi-Brittle Fracture," J. Eng. Mech., vol. 136, no. 1, pp. 40-50, 2009.

42. J. P. Lloyd, J. L. Lott, and C. E. Kesler, "Lloyd, J.P., Lott, J.L. and Kesler, C.E.," Univ. Illinois Urbana Champaign, Coll. Eng., no. Engineering Experiment Station, 1968.

43. A. A. Wells, George Rankin Irwin: 26 February 1907-9 October 1998. 2000.

44. A. T. Zehnder, Fracture Mechanics, Lecture No. Springer, 2012.

45. K. E. Kurrer, "The History of the Theory of Structures: From Arch Analysis to Computational Mechanics,” Int. J. Sp. Struct., vol. 23, no. 3, pp. 193-197, 2008.

46. The Aberdeen Group, "Some Notes on Concrete Fatigue," \#C620293, 1962.

47. H. W. Reinhardt, D. A. Hordijk, and H. A. Cornelissen, "Tensile Tests and Failure Analysis of Concrete," J. Struct. Eng., vol. 112, no. 11, pp. 2462-2477, 1986.

48. Z. P. Bazant and K. Xu, "Size Effect in Fatigue Fracture of Concrete," ACI Mater. J., vol. 88, no. 4, pp. 390-399, 1991.

49. A. Milenkovic and M. Pluis, "Fatigue of Normal-weight Concrete and Light-weight Concrete," 2000.

50. P. B. Cachim, J. A. Figueiras, and P. A. A. Pereira, "Fatigue Behavior of FiberReinforced Concrete in Compression," Cem. Concr. Compos., vol. 24, no. 2, pp. 211217, 2002.

51. J. Zhang and Q. Liu, "Determination of Concrete Fracture Parameters from a ThreePoint Bending Test," Tsinghua Sci. Technol., vol. 8, no. 6, pp. 726-733, 2003.

52. C. Gaedicke, J. Roesler, and S. Shah, "Fatigue Crack Growth prediction in Concrete Slabs," Int. J. Fatigue, vol. 31, no. 8-9, pp. 1309-1317, 2009.

53. P. Stroeven, "Low-cycle Compression Fatigue of Reinforced Concrete Structures," Procedia Eng., vol. 2, no. 1, pp. 309-314, 2010.

54. F. Aslani and R. Jowkarmeimandi, "Stress-strain Model for concrete under Cyclic Loading," Mag. Concr. Res., vol. 64, no. 8, pp. 673-685, 2012.

55. Y. Wang, X. Hu, L. Liang, and W. Zhu, "Determination of Tensile Strength and Fracture Toughness of Concrete using Botched 3-p-b Specimens," Eng. Fract. Mech., vol. 160, pp. 67-77, 2016.

56. S. Ayyad and M. Alawneh, "Effect of Concrete Parameters on Local Fracture Energy of Concrete," Int. J. Appl. Eng. Res., vol. 12, no. 5, pp. 793-796, 2017.

57. L. Susmel, Multiaxial Notch Fatigue. Elsevier, 2009.

58. G. Crupi and D. Taylor, "Residual Stresses and Fatigue Prediction Using the Theory of Critical Distances," Stress, vol. 50, no. 2, 2004. 